\title{
A SUBJETIVIDADE DO CIDADÃO BRASILEIRO: TESSITURAS ENTRE PSICANÁLISE, HISTÓRIA E DEMOCRACIA
}

\author{
Luciara Gervasio Itaqui \\ Psicóloga, Mestra em Psicologia pela PUCRS e Especializanda em Psicologia Clínica pelo Instituto \\ Fernando Pessoa
}

Silvio A. Lopes Iensen

Psicólogo, Mestre em Psicologia Social e da Personalidade, Doutor em Psicologia pela PUCRS, Professor Adjunto, Membro do Núcleo Docente Estruturante do Curso de Psicologia e do Comitê de Ética em Pesquisa com Seres Humanos do Centro Universitário Franciscano, Santa Maria, RS, Brasil

\section{Resumo}

O artigo pretende problematizar criticamente aspectos referentes à subjetividade no espaço social a partir do jargão "jeitinho brasileiro". Para tanto, busca-se compreender as relações entre o desamparo constitutivo do sujeito, a função fraterna e a democracia no Brasil, ao elucidar como se configura a subjetividade do cidadão brasileiro e seus desdobramentos no espaço social. A pesquisa realiza uma revisão narrativa de autores clássicos e contemporâneos da Psicanálise, do Direito e da História. Entende-se que em situações atuais de desamparo o sujeito reduz seus semelhantes a simples objetos visando ao próprio gozo, colocando a alteridade entre parênteses, fato que prejudica a efetivação de qualquer projeto democrático. Constata-se como consequência um mal estar generalizado no espaço social brasileiro, pois o sujeito percebe no "jeitinho brasileiro" uma via possível de descarga pulsional.

Palavras-chave: psicanálise; democracia; história.

\section{BRAZILIAN`S CITIZEN SUBJECTIVITY: A COMPOSITION BETWEEN PSYCHOANALYSIS, HISTORY AND DEMOCRACY}

\begin{abstract}
The article aims to critically discuss aspects related to subjectivity in social space from the jargon "jeitinho brasileiro". We seek to understand the relationships between the constituent helplessness of the subject, sibling's hole and democracy in Brazil, to elucidate the configuration of the Brazilian subjectivity citizen and its consequences in the social space. The search performs a narrative review of classic and contemporary authors of Psychoanalysis, Law and History. It has become clear that, in situations of profound abandoment, brasilian citizen will treat his fellows as objects to satisfy his needs, putting fundamental social conventions aside, and so harming any attempt at a democratic project. This results in a bad state of well-being for the Brazilian space, who see in their "jeitinho brasileiro" a means to ease their bad state of affairs.
\end{abstract}

Keywords: psychoanalysis; democracy; history. 


\title{
LA SUBJETIVIDAD DEL CIUDADANO BRASILEÑO: UNA COMPOSICIÓN ENTRE EL PSICOANÁLISIS, HISTORIA Y LA DEMOCRACIA
}

\begin{abstract}
Resumen
El artículo tiene como objetivo discutir críticamente los aspectos relacionados con la subjetividad en el espacio social de la jerga "jeitinho brasileiro". Con este fin, tratamos de entender las relaciones entre la impotencia constituyente del sujeto, la función fraterna y la democracia en Brasil, para dilucidar la configuración de la subjetividad brasileña y sus consecuencias en el espacio social. La búsqueda lleva a cabo una revisión narrativa de autores clásicos y contemporáneos del psicoanálisis, del derecho y de la historia. Se entiende que en situaciones reales de desamparo el ciudadano brasileño reduce al sujeto a objetos simples como su pedido al propio disfrute, poniendo entre paréntesis la alteridad, un hecho que socava la eficacia de cualquier proyecto democrático. Esto parece ser el resultado de un malestar general en el espacio social de Brasil como el sujeto percibe el "jeitinho brasileiro" como una posible ruta de la descarga pulsional.
\end{abstract}

Palabras claves: psicoanálisis; democracia; historia.

\section{INTRODUÇÃO}

A Psicanálise é um campo de investigação clínica e teórica que se propõe a compreender o sujeito como sujeito de inconsciente inserido em uma determinada cultura. Uma possibilidade de pesquisa é utilizar a teoria psicanalítica para realizar uma leitura da condição da subjetividade do cidadão brasileiro na contemporaneidade.

Sabe-se que a subjetividade, num primeiro momento, é o protótipo das relações que esse estabeleceu com seus pais e que, posteriormente, irá "reproduzir" no campo social. Nesse campo social, o sujeito convive em sociedade com seus iguais, ou seja, seus "irmãos", estabelecendo relações entre si.

Essas relações são, portanto, o resultado de tudo aquilo que o sujeito foi internalizando a partir de suas experiências do que é certo, do que é errado, os valores, as normas e as regras sociais. Para isso, é necessário que esses irmãos realizem algumas renúncias a fim de continuarem convivendo na coletividade: o sujeito deve abrir mão de seus desejos e de suas vontades individuais, caso contrário pode comprometer a vivência em sociedade.

A tradição psicanalítica, de acordo com Birman (2003), normalmente aborda a fraternidade dentro do enfoque familiar, no qual se evidencia o caráter da rivalidade. Sendo assim, compreende-se que o laço fraterno foi, de certa forma, negligenciado pela Psicanálise em função da prevalência atribuída à 
função paterna. Portanto, percebe-se que falar do tema é, em alguma medida, superar um obstáculo teórico.

Este artigo problematiza a construção da subjetividade do brasileiro e suas relações com o projeto democrático. Para tal, buscou-se fundamentar as relações entre a função fraterna, a democracia e o "jeitinho brasileiro" no espaço social. À luz de alguns textos clássicos sociais de Freud, como Totem e Tabu (1913/1996), Psicologia de Grupo e Análise do Ego (1921/1996), e também de outros autores no campo da Psicanálise, do Direito e da História que tratam sobre o sujeito, a subjetividade, a cultura e a democracia objetivou-se, a partir do jargão "jeitinho brasileiro", analisar não apenas de que modo se configuram os modelos de subjetivação do cidadão brasileiro, bem como compreender sua dinâmica no espaço social brasileiro.

Este artigo se justifica devido à condição atual das relações sociais no Brasil. Entende-se que buscar formas de articular os saberes sobre a subjetividade do brasileiro, a história do Brasil e o funcionamento do Estado pode auxiliar na compreensão do momento histórico vivido. Para tanto, pesquisaramse argumentos por meio de uma revisão narrativa com autores clássicos e atuais brasileiros sobre as temáticas citadas.

Segundo Rother (2007), "artigos de revisão narrativa são publicações amplas, apropriadas para descrever e discutir o desenvolvimento ou 'estado da arte' de um determinado assunto, sob o ponto de vista teórico ou contextual" ( $p$. v). Para a autora, esse tipo de revisão bibliográfica constitui-se de análise da literatura de livros, artigos de revistas "na interpretação e análise crítica pessoal do autor" (p. v). Assim, optou-se por esse formato de metodologia para o desenvolvimento do artigo.

\section{O ADVENTO DA CIVILIZAÇÃO E A HERANÇA BRASILEIRA}

Freud (1913) escreve sobre o mito da passagem da humanidade de um estado de barbárie a um protótipo de civilização a partir do assassinato do pai primitivo por seus filhos, os quais se sentiam impotentes diante de sua onipotência. Esse ato criminoso dá lugar ao desamparo, à lei e ao sentimento de culpa entre os filhos; sentimento esse que os une e os liga e que, em forma de herança, irá acompanhar a civilização.

Contudo, o referido assassinato, para Figueiredo (2000), potencializou a rivalidade entre os filhos, e a solução para tal deu-se pela via de algumas 
renúncias coletivas como: a interdição do incesto, da rapina, do canibalismo e do assassinato. Entende-se que isso se tornou obrigatório, pois, caso contrário, instalar-se-ia o caos e a luta de todos contra todos. Posteriormente, advém, em função dessas renúncias, a solidariedade fraterna.

Desde então, os filhos constituíram-se em uma associação fraternal fundamental, pelo fato de que, segundo Teixeira (2002), abandonaram a posição de filhos de um pai todo-poderoso, assumindo-se como irmãos. Porém, o que sucede ao ato do assassinato, para essa autora, é a afirmação da impossibilidade de que o lugar do pai venha a ser ocupado por algum dos irmãos em particular.

Paradoxalmente, a busca pela onipotência coloca-se como necessariamente impossível, propiciando a gênese de uma comunidade de iguais: os irmãos identificam-se na culpa e no arrependimento pelo assassinato (Freud, 1913). A culpa poderia ser elaborada e reparada sob a forma de constituição de ideais que representem o pai morto.

Ao desamparo que se seguiu à morte do pai, a função paterna, segundo Kehl (2000), instituiu-se como modo de amparo simbólico aos membros da comunidade. Assim, o crime compartilhado intensificou os laços fraternos e exigiu a produção de um ideal coletivo que funcionasse, ao mesmo tempo, para velar e legitimar o assassinato, a partir do qual os irmãos são forçados a se enfrentar com suas diferenças.

Ao contrário da relação que o senso comum estabeleceu entre fraternidade e igualdade, os irmãos são "iguais" ao se manterem filhos e submissos à tirania do pai. Nesse sentido, a substituição da tirania pela lei simbólica permite o aparecimento das diferenças: a divisão de tarefas, as diferentes habilidades, a discriminação dos lugares segundo a ordem de nascimento, entre outras. Entende-se que, entre tantas questões, parece ser tarefa da fratria fazer operar a função paterna, pois o pai simbólico está sendo encarnado nas renúncias aceitas pelos irmãos. A lei estabelecida pelo acordo entre os irmãos exige a renúncia de algumas satisfações instituais como condição para se pertencer à coletividade (Kehl, 2000).

Percebe-se que toda civilização carrega consigo essa herança cultural e histórica contributiva à constituição de sua subjetividade, herança comum a todos os humanos, mas que, no cidadão brasileiro, concretiza-se com particular peculiaridade. A maneira como o brasileiro lida com a realidade no espaço social é própria, podendo ser nomeada, conforme Figueiredo (2000), "fraternidade 
transgressora" ou "jeitinho brasileiro". Entende-se ser um modo particular de fraternidade do cidadão brasileiro que pode comprometer a abertura de espaço para projetos fraternos e democráticos.

Freud (1921) considera que a massa dota os indivíduos de uma espécie de mente coletiva que os faz sentir, agir e pensar de maneira muito diferente daquela que faria se estivesse isolado do grupo. Nesse sentido, pode-se pensar que, no espaço social do Brasil, manifeste-se mais fortemente o modo de agir do cidadão brasileiro, seu jeitinho.

Sob essa perspectiva, pode-se perceber que o sujeito prima pelo gozo, havendo pouca ou quase nenhuma preocupação com a alteridade, fator que pode comprometer a instalação da democracia. Segundo Figueiredo (2000), a fraternidade transgressora do "jeitinho", forma bizarra de fraternidade que surge no Brasil, destroça rapidamente qualquer projeto fraterno e democrático. Portanto, o cidadão brasileiro, ao não medir esforços em ferir normas sociais e/ou ludibriar leis, instala uma relação ímpar social, ou seja, busca dar "um jeitinho".

Esse modo de agir do brasileiro no espaço social pode ter origem desde o tempo da descoberta do Brasil. Sabe-se que, em regimes absolutistas, as determinações são estabelecidas pelo monarca, sem a participação democrática. Nesse sentido, cabe compreender as particularidades do regime monárquico no Brasil como possibilidade de ser a origem para o jeito de burlar o estabelecido.

\section{A HISTÓRIA DESDE A "DESCOBERTA"}

A coroa portuguesa veio para o Brasil, segundo Gomes (2010), em fuga devido à ameaça de Napoleão invadir Portugal. A partir desse fato, pode-se perceber que a monarquia não se instala no Brasil com o propósito de desenvolver a Colônia, mas, sim, de utilizar as terras além-mar para instalar a sede de um governo distante da Metrópole. Assim, percebe-se uma condição ímpar na história da monarquia brasileira. A partir das condições históricas brasileiras, pode-se pensar em formas de articular inferências sobre a situação atual da sociedade.

Ribeiro (2010) afirma que, durante o Brasil Colônia, o compadrio e o apadrinhamento regiam a distribuição de cargos judiciários, que poderiam ser comprados ou cedidos como recompensa. Para as classes não nobres, alcançar a 
magistratura era uma das poucas maneiras de se obter um título de fidalguia para três gerações (Ribeiro, 2010).

Para o autor, os juízes, vindos de Portugal para o Brasil sob a promessa de enriquecimento lícito fácil, prorrogavam ao máximo sua estada no País. Tornarse funcionário público conferia certeza de que não faltariam oportunidades para a realização de interesses econômicos privados. (Ribeiro, 2010). Nessa situação, percebe-se uma forma de jeitinho, de transformar a coisa pública em privada. Pode-se verificar que à época o funcionamento da justiça focava-se mais nos interesses pessoais de seus funcionários do que propriamente em prol do País.

Segundo Venâncio e Priore (2010), houve no Brasil do século XIX, durante o Segundo Reinado, o parlamentarismo às avessas, um bom exemplo de prática que visou na época atender apenas aos interesses do imperador, dando-lhe total poder para escolher os ministros e dissolver a câmara dos deputados. Nos sistemas parlamentaristas europeus, o poder legislativo tinha força para comandar a nação; no entanto, no Brasil, isso não ocorria.

Dom Pedro II, devido ao poder moderador, subordinava todos os demais poderes do Estado e, por esse motivo, o parlamentarismo brasileiro foi chamado de "Parlamentarismo às Avessas" (Venâncio e Priore, 2010). Para os autores, na Inglaterra, que adotava o parlamentarismo, dizia-se entre os ingleses que: o rei reina, mas não governa. No Brasil, o centro do poder político continuava sendo o imperador. Entre os brasileiros, dizia-se que: o rei reina, ri e rói. Reina sobre o Estado, ri do parlamento e rói o povo (Venâncio \& Priore, 2010).

\section{TECENDO A HISTÓRIA E A ATUALIDADE}

Compreende-se que os motivos relatados acima possam representar uma provável origem histórica do "jeitinho" particular de dar conta das questões no espaço social. Nesse sentido, entende-se que o imperador atende às suas demandas de desejo em detrimento do povo e do parlamento. As consequências da forma peculiar de vazão pulsional permite traçar um panorama de como se vai configurar a subjetividade que circula no espaço social brasileiro atualmente.

Atualmente, o funcionamento do Estado brasileiro é outro. Sabe-se que o projeto democrático vem se estruturando desde a abertura política com o fim da ditadura militar. No entanto, verifica-se que o sistema político brasileiro atual não é muito diferente da realidade supracitada. 
Pode-se equiparar a atitude do imperador durante a Monarquia com o que compete ao Presidente da República na democracia. Na atualidade, embasado na Constituição Brasileira vigente, o Presidente indica os Ministros do Supremo Tribunal Federal (STF). No entanto, esse fato pode colocar coloca em suspensão a neutralidade dos Ministros na hora de um julgamento no que diz respeito às atividades políticas exercidas, visto ser o tribunal que realiza os julgamentos referentes à Constituição, aos políticos - devido ao fórum privilegiado - e ao próprio Presidente da República.

A essência da democracia reside, de acordo com Montesquieu (1897), na separação dos poderes (Legislativo, Executivo e Judiciário) para que haja o controle de um poder sobre o outro a fim de que a ordem constitucional seja alcançada. De acordo com Guedes (2008), o primeiro poder é exercido pelo Congresso Nacional composto pela Câmara dos Deputados e pelo Senado Federal, com a função de editar regras gerais, abstratas, impessoais e inovadoras da ordem jurídica, as leis. O segundo poder é composto pelo Presidente da República e pelos Ministros de Estado por ele indicados, com a função de administrar máquina pública; finalmente, o terceiro poder tem como objetivo traduzir a realidade efetiva do direito, para aplicar a justiça nas relações humanas, sendo composto pelo Supremo Tribunal Federal e o Superior Tribunal de Justiça.

Para Guedes (2008: 9)

Critica-se essa forma de composição do Supremo Tribunal Federal, por estabelecer um vínculo indesejado entre o ministro indicado e o Presidente da República que o indicou. Este vínculo acaba por ferir, fatalmente, a independência e imparcialidade que necessitaria ter, todo o juiz, na hora de julgar. O ministro, tendo sido indicado pelo Presidente, pertencente a determinado partido político, certamente que não irá julgar contra àqueles, salvo, por óbvio, raríssimas e honrosas exceções; sendo que mesmo estas exceções têm caráter duvidoso, considerando a pressão popular e jornalística à época do julgamento.

Nesse cenário, estabelece-se um vínculo questionável entre o Presidente da República e os Ministros do STF, que, de alguma maneira, fere a independência dos poderes, sugerida por Montesquieu, e a imparcialidade que necessita ter todo e qualquer juiz na hora de julgar. Portanto, entende-se que a indicação do Ministro pode ser considerada como um subterfúgio a serviço de atender as demandas de desejo do Presidente. Afinal, a imparcialidade e a independência 
entre os poderes podem estar comprometidas, na medida em que se cria um vínculo questionável entre o Ministro e o Presidente.

Assim, constata-se que o político cria leis que contemplam o seu gozo e parece não atender às demandas do restante dos cidadãos. Percebe-se que o cidadão comum é colocado de lado, pois a lei tende a privilegiar o político e/ou uma pequena parcela da população. Pode-se encontrar no atual funcionamento do espaço social do Brasil, segundo Birman (2012), "a marca profunda das tradições escravagista e patrimonialista que perpassam as relações sociais no Brasil, onde as classes populares são depredadas pelas elites, pela mediação do Estado" (p. 303).

Nesse sentido, entende-se que se cria uma espécie de diferença entre os irmãos, logo, a fratria fica ameaçada. O que o cidadão faz quando fica esquecido pelo político? Pode-se pensar que, ao ser esquecido por seus representantes legais, o cidadão utiliza-se do "jeitinho brasileiro" para atender às demandas de desejo. Ao copiar o modo de ser e agir do político o cidadão pode comprometer a fatria.

\section{A CONSTITUIÇÃO PSÍQUICA DO SUJEITO}

Sabe-se que o sujeito é um ser social. Para Bleichmar (1994), um iniciante na vida, não tem como dissipar toda a excitação interna desenvolvida, visto que essa não tem na via motora condição de descarga. A criança necessita de um outro capaz de dar cabo a excitação, para realizar o que Freud (1895/1996) denominou de ação específica. Entende-se que após essa relação primária com o outro, vão ocorrer novas configurações em que o sujeito vai, também, sentir-se desamparado. Estar vivo significa enfrentar várias situações que demandam pelo amparo do outro, pois o sujeito é, inevitavelmente, um ser sujeito à condição de desamparo.

O desamparo, para Moreira (2005), faz com que o eu perceba a importância inquestionável do outro para sua sobrevivência. Sem o encontro e o reconhecimento da alteridade, o eu sucumbiria no desamparo. O reconhecimento do outro como fundamental na constituição psíquica do sujeito e na garantia da vida biológica conduz à necessidade de respeito e preservação do laço vital que une o eu e o outro.

Segundo Moreira (2005), o processo de subjetivação é intensamente marcado pelo narcisismo e pelo complexo de Édipo, via de ingresso no mundo 
simbólico, na linguagem e na cultura. A cena edípica, para a autora, traduz teoricamente a contenção da sexualidade através da proibição do incesto e a vivência do Édipo também possibilita a contenção da agressividade através do superego, o que pode introduzir o encontro com a alteridade.

A vivência do narcisismo primário é a onipotência que diz respeito ao eu ideal que confere ao sujeito a possibilidade de acreditar que possa impor seus ideais e instituir sua lei. Para Hornstein (1989, p. 176),

o sentimento de onipotência da criança identificada com o ideal é severamente questionado pela experiência vivida, seu eu não pode persistir na posição de plenitude, e a criança (mediante crise da castração) constituirá um ideal de eu com o qual tentará recuperar a perfeição narcísica primordial, mas às custas de um rodeio identificatório que procurará diminuir a distância do eu com o ideal.

Para o autor, o Ideal de eu estará investido pela libido narcisista, mas constituir-se-á a partir de valores, críticas e exigências presentes no sistema de desejos parentais que, por sua vez, refletem o sistema de valores do espaço social. Portanto, no eu ideal são parcos os valores de alteridade, reciprocidade e reconhecimento das necessidades do outro.

Para Birman (2012), a subjetividade oscila continuamente entre os polos alteritário e narcísico que fundam o sujeito. Para o autor, a oscilação do sujeito entre os polos está na estrita dependência de que as formas organizadas do poder social permitam ou não a satisfação de suas demandas pulsionais. Nesse sentido, pode-se inferir que a subjetividade do cidadão brasileiro esteja pendendo para o polo narcísico, o que certamente contribui para um funcionamento no espaço social de caráter ainda mais narcísico, em detrimento do polo alteritário.

Assim, compreende-se que há dificuldade por parte do cidadão brasileiro que se utiliza do jeitinho brasileiro - no reconhecimento do outro com consequente comprometimento das relações alteritárias. O devir da fratria parece ficar comprometido.

Nesse sentido, pensa-se em um sistema psíquico que pode auxiliar o sujeito a regular as ações no espaço social. Entende-se que o superego, herdeiro do Complexo de Édipo, é responsável por agregar um conjunto de interditos, os quais o ego do sujeito deve obedecer para regular as demandas pulsionais de satisfação e de gozo nas relações com o outro. O sentimento de culpa aparece como uma das modalidades de relação com a alteridade. Assim, entende-se a 
culpa como um fator estruturante da civilização e, consequentemente, da sociedade brasileira.

Quando o sujeito vive o complexo edípico, revive psiquicamente a cena do assassinato do pai somado ao sentimento de culpa e a constatação dos interditos e das proibições. De fato, esse reviver não é consciente, entretanto ocorre no âmbito do outro-alteritário, a saber, o Inconsciente. Os novos sujeitos não cometeram o ato, mas tiveram a intenção de cometê-lo; a intenção é suficiente para padecer com a culpa, angustiante enquanto experiência, porém estruturante em seu efeito (Moreira, 2005).

Para Teixeira (2002), cada sujeito é singular, todavia há a possibilidade de um compartilhamento da vida social e do uso de uma língua, uma vez enlaçada ao simbólico. No entanto, ainda que viabilizado o compartilhamento social e o uso comum de uma língua, a singularidade "cobra o seu preço" na forma de confrontos, desentendimentos e toda a gama de conflitos que impedem que a paz e o consenso sejam permanentes nas relações entre os seres humanos, pois cada sujeito busca de maneira singular a satisfação de seu desejo.

Para Bauman (2011), a satisfação e a felicidade humana somente podem ser obtidas na interação de dois valores: a segurança e a liberdade. O autor afirma que "segurança sem liberdade é escravidão; liberdade sem segurança é um completo caos" (Bauman, 2011, 00:22:37). O autor assevera que esse é o dilema da humanidade ainda não resolvido. Assim, entende-se que o cidadão, ao valer-se do jeitinho no meio social, coloca em suspensão a possibilidade da liberdade, pois, ao preocupar-se em efetivar seus desejos, deixa a segurança do outro ameaçada.

Para Freud (1913/1996), a civilização é garantida através da culpa, ou seja, da agressividade modificada a partir do encontro com a verdade do desamparo, que aponta para o outro como fim em si, e não como meio. O desamparo coloca o sujeito em uma condição de insocorribilidade, pois necessita do outro para atender as demandas que sozinho não consegue dar conta. Portanto, há uma dívida eterna ao outro.

Nesse cenário, compreende-se que a agressividade dirigida a outrem deve ser introjetada, e nesse processo ocorre uma transformação da agressividade em sentimento de culpa. A percepção da alteridade se reinscreve, segundo Moreira (2005), ao trazer o sentimento de culpa por se ter desejado agredir o outro, não 
só na sua dimensão de pessoa, mas também em suas dimensões narcísica e objetal.

Entende-se que o sujeito sente-se culpado por desejar agredir aquele que no enlaçamento suporta com ele o desamparo. Assim, a verdade do desamparo possibilita a percepção da dependência entre os sujeitos. Pode-se pensar que o jeitinho brasileiro não deixa de ser uma forma modificada de agressão encontrada entre os irmãos brasileiros. A agressão ocorre no âmbito do Outro compreendido como um meio, compreendido como objeto de gozo, pois, através de uma atitude infantil, o sujeito utiliza o outro como meio de descarga pulsional, tentando livrar-se da castração.

\section{O CENÁRIO POLÍTICO E A SUBJETIVIDADE BRASILEIRA}

A democracia (do grego demos, "povo", e kratos "autoridade"), como sistema político, reconhece à maioria o direito de participar da direção e gestão dos assuntos públicos e sociais. Isso significa a capacidade de o maior número de pessoas viver a sua vida individual de maneira condizente com aquilo que é permitido em sociedade, ou seja, é necessário, por vezes, abrir mão do desejo individual em prol do desejo coletivo. Contudo, entende-se que isso geralmente não se observa no cidadão brasileiro que se utiliza do "jeitinho brasileiro" como mediador das relações.

Nesse sentido, compreende-se que se pode abrir mão do desejo individual em prol do desejo coletivo quando se reconhece a existência e a importância do outro, o que não se percebe eficientemente na sociedade brasileira. As desigualdades sociais - característica de nosso País - e as experiências persistentes de insatisfação com relação às decisões políticas - em que privilegia o próprio político - podem despertar e aflorar a crença arcaica e infantil de que os outro obteve aquilo que ao sujeito é negado, sendo, então, possível um encontro com o objeto primeiro perdido. Nesse cenário, pode-se pensar na apropriação da coisa pública como sendo privada.

Os valores, os ideais, as normas e leis sofrem a usura do tempo através dos usos e abusos além do desgaste proveniente do confronto, na maioria das vezes frustrante e decepcionante com as experiências vividas, pois a entrada no laço social implica a castração do gozo como afirma Moreira (2005). Soma-se, ainda, o fato da esperança de que as renúncias de um sujeito serão contrabalançadas pelas renúncias alheias e de que ninguém alcançará a felicidade suprema. No 
entanto, ao verificar o funcionamento da democracia brasileira, percebe-se que o gozo de uns é atendido a partir do sacrifício do gozo dos muitos outros.

Entende-se, portanto, que esse funcionamento democrático brasileiro contribui para o boicote à durabilidade de confiança do sujeito brasileiro na civilização, na cultura, nas leis brasileiras e nas renúncias pulsionais. Assim, parecem prevalecer algumas formas de o cidadão brasileiro agir no espaço social: violência, agressividade, roubo e corrupção, entre outras. Trata-se de características bem visíveis das relações no espaço social do Brasil de hoje.

Sabe-se que a produção da civilização coloca a discussão ética como prioridade, na medida em que anuncia o encontro entre o eu e o outro como a base de sua constituição, como aquilo que especifica o humano. Parece, nesse sentido, que a realidade do Brasil, a qual cada cidadão, ao longo de suas experiências, vai internalizando, é composta por situações nas quais o imperativo do gozo busca consumar-se através de atos e atitudes advindas do polo narcísico enquanto há esvaziamento do polo alteritário.

Assim, estabelece-se um círculo de identificações no qual o polo narcísico evidencia-se como um modelo adequado a dar conta da subjetividade do cidadão brasileiro. Aquilo que é cotidiano é tido como "normal", como algo a ser seguido. Nesse sentido, entende-se a importância da compreensão das condições históricas, institucionais e culturais que contribuem para a existência e atualização do "jeitinho brasileiro" como uma forma de subjetivação específica de um povo que compartilha um funcionamento semelhante em um mesmo espaço social.

Dessa forma, pode-se afirmar que o cidadão brasileiro, em sua dinâmica no espaço social do Brasil, é fortemente marcado por seu polo narcísico, ou seja, a fim de que ele possa satisfazer suas necessidades e desejos, irá lançar mão de possibilidades que the convenham na obtenção de satisfação, mesmo que para isso seus compatriotas sejam reduzidos de sujeitos a objetos de gozo. A partir dessa lógica, fica evidente o "jeitinho brasileiro" de transitar pelo espaço social brasileiro.

Pode-se pensar que o cidadão brasileiro desenvolve características específicas em sua subjetividade devido ao meio social e às relações que nele são estabelecidas. Diferentemente do que pode ocorrer em outros países, compreende-se que o cidadão brasileiro acabou por desenvolver uma forma particular de subjetividade no sentido do conceito de Bleichmar (2009). Para a 
autora, a subjetividade é a relação construída do sujeito com o meio, o modo de ser e estar no mundo, produzido pela cultura e que pode sofrer mudanças com o passar dos tempos. Apesar de ser o mesmo modelo democrático que baliza as relações sociais no Brasil e em outros países, sabe-se que a subjetividade do cidadão brasileiro tende ao "jeitinho brasileiro" como modelo de relacionamento no espaço social desde os tempos da descoberta do País.

\section{CONSIDERAÇÕES FINAIS}

A realização deste artigo possibilitou a compreensão dinâmica que marca a relação da subjetividade do sujeito brasileiro no espaço social e político. Portanto, pode-se afirmar que as características das relações sociais são efeitos da subjetividade do brasileiro. O jeitinho brasileiro é, nesse contexto, uma forma particular de administrar a descarga pulsional.

O sentimento de desamparo, a dificuldade no reconhecimento da alteridade e da culpa e a tentativa de retorno ao narcisismo primário, no qual a alteridade ainda não estava presente, são ferramentas teóricas importantes para auxiliar o entendimento do "jeitinho brasileiro" de administrar a descarga pulsional e, consequente, realização do desejo. Nesse sentido, ao sentir-se numa situação de desamparo, o sujeito reduz os irmãos a simples objetos de gozo e coloca, então, a alteridade suspensa na tentativa infantil e arcaica de obturar a falta que lhe é constitutiva e que não se obtura com os objetos da ordem do real. Conforme Birman (2006), esse modelo de subjetividade surge como tentativa de lidar com o desamparo, conduzindo ao incremento da individualidade, do narcisismo, da violência e da crueldade.

As indicações dos Ministros do STF realizadas pelo Presidente da República não deixam de ser um "jeitinho brasileiro", através do qual um pequeno grupo atinge o gozo à medida que a maioria fica desassistida. Sabe-se que a justiça brasileira funciona a quem tem determinado poder. Não seria a democracia ao contrário? Assim como o pequeno grupo privilegiado, o cidadão brasileiro, num funcionamento que pende mais para o polo narcísico, visa à sua satisfação ao conceber o outro como um fim para atingir o gozo e não como um meio. Essa atitude compromete as relações alteritárias e por consequência os princípios da democracia.

Constata-se que o Brasil tem um funcionamento democrático característico do povo que o habita, ou seja, das particularidades das relações culturais 
construídas no espaço social. Dessa forma, pode-se considerar que a política das relações entre os sujeitos brasileiros pode estar refletida na política institucional.

Percebe-se uma particularidade institucional na questão das escolhas dos Ministros. Sabe-se que em outros países o funcionamento das recomendações à suprema corte é igual a do Brasil. No entanto, constata-se o modo de funcionar do STF no julgamento relacionado ao "mensalão". Nota-se, por meio dos votos de alguns Ministros, o comprometimento com quem o indicou. Cabe relembrar o que se evidencia em Guedes (2008). A autora afirma que o Ministro só julgará contra aquele que o pôs no cargo, em raras e honrosas exceções, "sendo que mesmo estas exceções têm caráter duvidoso, considerando a pressão popular e jornalística à época do julgamento" (p.09). Sabe-se da grande pressão da impressa brasileira à época do julgamento, e, mesmo assim, nota-se o compadrio das indicações. Ao perceber os votos de certos ministros, era possível caracterizar a origem de suas indicações.

Dessa maneira, o estabelecimento da democracia fica prejudicado. 0 princípio necessário da democracia, que é a independência dos três poderes Executivo, Legislativo e Judiciário - é afetado e compromete um projeto democrático de direito e de fato. Portanto, para que haja um projeto democrático, o irmão deve ser reconhecido como outro, porque na democracia o outro é concebido como um meio para que o bem comum seja alcançado.

O descaso do Estado Brasileiro no reconhecimento da cidadania como uma via possível de descarga pulsional reside no fato de que ele próprio - os representantes dos poderes - tem dificuldade no reconhecimento da alteridade. Nesse sentido, pode-se afirmar que emanam ciclos de identificações que aos poucos legitimam o outro como objeto de gozo, o que infla o polo narcísico e, por consequência, ameaça a fratria e a democracia.

No entanto, se o sujeito conseguir utilizar o espaço público para reivindicar seus direitos e exercer a cidadania como uma forma de descarga pulsional - de sublimação de sua agressividade -, esta, de alguma forma, a lutar pela democracia e pela fratria. Pensa-se que o espaço público pode ser efetivamente público à medida que o cidadão brasileiro reconheça e lute pelo seu direito e pelo do outro como um irmão. Assim, a subjetividade do cidadão brasileiro se fortalece nas relações alteritárias, contribuindo, talvez, para a efetivação de um projeto fraterno e democrático de direito e de fato. 


\section{REFERÊNCIAS}

Bauman, Z. (2011). Diálogos com Zygmunt Bauman: Fronteiras do pensamento. Disponível em https://www.youtube.com/watch?feature=player_embedded\&v=POZcBNoD4A.

Birman, J. (2003). Fraternidades: Destinos e impasses da figura do pai na atualidade. PHYSIS: Rev. Saúde Coletiva.

Birman, J. (2006). Arquivos do mal-estar e da resistência. Rio de Janeiro: Civilização Brasileira.

Birman, J. (2012). Mal-estar na atualidade: A psicanálise e as novas formas de subjetivação. 9aed. Rio de Janeiro: Civilização Brasileira.

Bleichmar, S. (1994). A fundação do inconsciente: Destinos de pulsão, destinos do sujeito. Porto Alegre: Artes Médicas.

Bleichamar, S. (2009). El desmantelamiento de la subjetividad: Estallido del yo. Buenos Aires: Topía Editorial.

Figueiredo, L. C. (2000). Sobre pais e filhos: Mazelas da democracia no Brasil. Em: KEHL, Maria Rita (Org). Função fraterna. Rio de Janeiro: Relume Dumará.

Freud, S. (1912). Totem e tabu. Em: Edição standard das obras psicológicas completas de Sigmund Freud. vol. XIII. Rio de Janeiro: Imago, 1996.

Freud, S. (1921). Psicologia de grupo e análise do ego. Obras Completas. Volume XVIII. Rio de Janeiro: Imago, 1996.

Gomes, A. M. (2010). O exemplo do Brasil no crepúsculo da monarquia portuguesa. Navegações, 3(2), 164-170.

Guedes, J. S. (2008). Separação dos poderes? O poder executivo e a tripartição de poderes no Brasil. Acessado em: 05 de novembro de 2010 de http://www.facs.br/revistajuridica/edicao_fevereiro2008/discente/corpodisc ente.htm

Hornstein, L. (1989) Introdução à psicanálise. Trad. Maria Angela Santa Cruz. São Paulo: Editora Escuta.

Kehl, M. R (Org) (2000). Função fraterna. Rio de Janeiro: Relume Dumará.

Montesquieu, C. de S. B. (1987). O espírito das leis. Trad. Pedro Vieira Mota. São Paulo: Ediouro. 
Moreira, J de O. (2005). A alteridade no enlaçamento social: Uma leitura sobre o texto freudiano "O mal-estar na civilização". Acessado em: 05 de janeiro de 2014 de: http://www.scielo.br/scielo.php?script=sci_arttext\&pid=S1413$294 \times 2005000200016$

Ribeiro, I. L. (2010). Patrimonialismo e personalismo: A gênese das práticas de corrupção no Brasil. Anais do XIX Encontro Nacional do CONPEDI. Fortaleza.

Rother, E. T. (2007). Revisão sistemática X revisão narrativa. Acta Paulista de Enfermagem, 20(2), v-vi. Acessado em: 05 de fevereiro de 2014 de: http://www.redalyc.org/articulo.oa?id=307026613004

Teixeira, L. C. (2002). Função paterna, frátria e violência: Sobre a constituição do socius na psicanálise freudiana. Psico-USF, 7(2), 195-200.

Venâncio, R \& Priore, M del. Uma breve história do Brasil. Ed: Planeta, 2010.

Violante, M. L. V. (2000). Pesquisa em psicanálise. Em: R. A. P. Filho, N. C. Junior \& M. D. Rosa (orgs). Ciência, pesquisa, representação e realidade em psicanálise. São Paulo: Casa do Psicólogo: EDUC.

Contato: luciaraitaqui@gmail.com, silvioiensen@gmail.com

Recebido em: 11/04/2014

Revisado em: 15/05/2014

Aceito em: 15/07/2014 